Original article

Red Beetroot Thematic Issue

\title{
High-Speed Counter-Current Chromatography in Separation and Identification of Saponins from Beta vulgaris L. Cultivar Red Sphere
}

\author{
Aneta Spórna-Kucab*, Stawomir Wybraniec \\ Department of Analytical Chemistry, Institute C-1, Faculty of Chemical Engineering and Technology, \\ Cracow University of Technology, ul. Warszawska 24, 31-155 Cracow, Poland
}

Key words: saponins, Beta vulgaris L., high-speed counter-current chromatography

Saponins, natural plant compounds exhibiting health benefits, were extracted from B. vulgaris L. cultivar (cv.) Red Sphere and separated by high-speed counter-current chromatography (HSCCC) in a new solvent system composed of: TBME-BuOH-ACN- $\mathrm{H}_{2} \mathrm{O}(1: 2: 1: 5, v / v / v / v)$. The system was used in the head-to-tail mode. The flow rate of the mobile phase was $3 \mathrm{~mL} / \mathrm{min}$ and the column rotation speed was $860 \mathrm{rpm}$. The retention of the stationary phase was $47 \%$. The LC-MS/MS analyses were performed for the identification of separated saponins in the crude extract as well as HSCCC fractions..

Significantly different elution orders of the analytes were observed in the HSCCC and HPLC systems, indicating the complementarity of both the techniques in the fractionation of saponins. Moreover, during the HSCCC separation, acetal-type saponins were eluted faster than pentose/ hexose-type saponins and then dioxolane-type saponins. The separation of saponins in the HSCCC solvent system enabled the fractionation and preconcentration of 13 saponins for further fragmentation experiments in the LC-MS/MS system. Nine saponins were detected for the first time ever in B. vulgaris L. cv. Red Sphere.

\section{INTRODUCTION}

The widely described health benefits of red beet root (Beta vulgaris $\mathrm{L}$.) have led to increased scientific and consumer interest in this vegetable [Chhikara et al., 2019; Clifford et al., 2015; Nemzer et al., 2011]. Red beet is rich in several bioactive compounds which can be useful in the treatment of many diseases, such as hypertension, atherosclerosis, type 2 diabetes, and dementia [Clifford et al., 2015; Nemzer et al., 2011].

Beet root is a rich source of highly bioactive saponins which are associated with haemolytic [Voutquenne et al., 2003]; molluscicidal [Huang et al., 2003]; anti-inflammatory [da Silva et al., 2002]; antifungal, anti-yeast activity, and antibacterial [de Lucca et al., 2002]; as well as with antiparasitic activity [Traore et al., 2000]. They exhibit also cytotoxic, antitumoric [González et al., 2003], and antiviral effects [Gosse et al., 2002].

Saponins are divided into two groups: steroidal saponins and triterpenoid saponins. Some authors distinguish a third group called steroidal amines or steroidal alkaloids [Bruneton, 1995]. Triterpenoid saponins are a common group of saponins consisting of a triterpenoid aglycone containing 30 carbon atoms and comprising a pentacyclic structure [Sparg et al., 2004]. Triterpene saponins are glycosides

\footnotetext{
* Corresponding Author: E-mail: anetasporna@chemia.pk.edu.pl (A. Spórna-Kucab)
}

containing one or two sugar chains connected via an ester to $\mathrm{C}-28$ or ether to $\mathrm{C}-3$. According to the literature, hexoses, pentoses, 6-deoxyhexoses, and uronic acids are primary sugar units in triterpene saponins. Moreover, the uronic acid moiety is bonded only to C-3 [Mikołajczyk-Bator et al., 2016; Yoshikawa et al., 1996, 1998]. So far, oleanolic as well as hederagenin, akebonoic, and gypsogenin aglycones were identified in red beet roots [Mikołajczyk-Bator et al., 2016].

The profile of triterpenoid saponins in the roots of red beet cv. Red Sphere (Beta vulgaris L.) was previously studied using reversed liquid chromatography and mass spectrometry by Mroczek et al. [2012, 2019] and 13 saponins have been described wherein 11 compounds contained oleanolic acids aglycone. Another research on saponins in red beet root cv. Nochowski was that by Mikołajczyk-Bator et al. [2016], wherein 44 saponins were characterized, including 22 compounds that were described for the first time ever. Moreover, 27 saponins, which contained oleanolic acids aglycone, were identified using the LC-MS/MS/MS technique.

The structural characterisation of triterpenoid saponins in the roots of red beet is very difficult and time-consuming due to the complexity of the matrix [Mikołajczyk-Bator et al., 2016; Mroczek et al., 2012, 2019], therefore, fractionation of the crude samples enables faster and more accurate identification of significantly preconcentrated saponins [Thakur et al., 2014]. High-speed counter-current chromatography is a very important technique in the separation of natural plant compounds [Jerz et al., 2008, 2010; Spórna-Kucab 
et al., 2019; Wybraniec et al., 2009, 2010] which enables subsequent identification of new structures of target compounds [Choi et al., 2015; Figueiredo et al., 2017]. Moreover, HSCCC is perceived as a rapid and convenient technique for the isolation of saponins [Thakur et al., 2014]. Additionally, it is worth noting that during HSCCC separations, no loss of target compounds arising from their irreversible adsorption onto the solid matrix is observed, often taking place in the conventional liquid chromatography, because mobile and stationary phases are liquids [Spórna-Kucab et al., 2013a, 2015; 2016; 2018a,b].

In this study, a crude saponin mixture from Beta vulgaris $\mathrm{L}$. cv. Red Sphere was separated for the first time by semi-preparative HSCCC in a new solvent system. The HSCCC technique enabled the identification of new saponins in Beta vulgaris L. cv. Red Sphere.

\section{MATERIALS AND METHODS}

\section{Plant material and reagents}

Red beet roots (Beta vulgaris L.) of cv. Red Sphere were purchased from a local market in Cracow in June 2019. The roots were grounded and forthwith extracted.

For the HSCCC experiments and for analytes extraction, HPLC-grade butanol $(\mathrm{BuOH})$, tert-butylmethylether (TBME), acetonitrile (ACN), and ethanol (EtOH) were obtained from Avantor Performance Materials Poland S.A. (Gliwice, Poland). LC-MS grade acetonitrile and formic acid (purity $\geq 98 \%$ ) were obtained from Sigma-Aldrich (St. Louis, United States).

\section{Crude pigment extracts}

Fresh and grounded in a blender (thermomix, Vorwerk, Wuppertal, Germany) roots from Beta vulgaris L. cv. Red Sphere $(1.5 \mathrm{~kg})$ were extracted by maceration three times for $1 \mathrm{~h}$, using $1 \mathrm{~L}$ of $80 \%$ ethanol each time. The extract obtained was filtered and pre-concentrated by a rotary evaporator (Heidolph, Schwabach, Germany) at $25^{\circ} \mathrm{C}$ to $100 \mathrm{~mL}$ under reduced pressure. Then, the extract was loaded into an $\mathrm{RP}-\mathrm{C}_{18}$ cartridge pre-conditioned with ethanol and water. The cartridge was washed with water and then with $10 \%, 20 \%$, $50 \%$, and $100 \%$ ethanol. The eluates were pre-concentrated by a rotary evaporator at $25^{\circ} \mathrm{C}$ and freeze-dried. The eluates obtained were monitored by LC-DAD-ESI-MS/MS. Finally, $196.6 \mathrm{mg}$ of saponins were eluted with $50 \%$ ethanol and $115.4 \mathrm{mg}$ of saponins with $100 \%$ ethanol.

\section{HSCCC separation}

The separation of saponins (Table 1) was accomplished on a semi-preparative AECS QuikPrep HSCCC J-type hydrodynamic chromatograph (London, United Kingdom) with $121 \mathrm{~mL}$ capacity and $2.0 \mathrm{~mm}$ i.d..

A new biphasic system consisting of TBME-BuOH-ACN$-\mathrm{H}_{2} \mathrm{O}(1: 2: 1: 5, v / v / v / v)$ was prepared for the HSCCC run. The solvent system was prepared in a separating funnel. Required volumes of solvents were mixed in a separating funnel. Then, the two phases for the HSCCC separation were divided shortly before use and degassed by ultrasonication for $10 \mathrm{~min}$. The upper organic phase was used as the station- ary phase and the lower aqueous phase as the mobile phase in the 'head-to-tail' mode. Per definition, this mode of separation is named reversed-phase comparable to $\mathrm{C}_{18}$-HPLC also using the aqueous phase as the eluting solvent phase [Spórna-Kucab et al., 2019; Wybraniec et al., 2010].

The HSCCC column was entirely filled with the upper phase (stationary phase). The rotation of the HSCCC instrument was started at $860 \mathrm{rpm}$. Then, the lower aqueous phase (mobile phase) was pumped at a flow rate of $3.0 \mathrm{~mL} / \mathrm{min}$ (K-501 pump, Knauer, Berlin, Germany).

After column equilibration, the sample solution was injected by an injection valve. This solution was prepared by dissolving $300 \mathrm{mg}$ of the extract in $4 \mathrm{~mL}$ of the lower phase. The effluent from the column was continuously monitored with a UV-Vis detector at $210 \mathrm{~nm}$ (Knauer). Twelve fractions were collected in a fraction collector (Foxy Jr., Knauer) at 2-min intervals and then analysed by LC-DAD-ESI-MS/MS (Figures 1-3). The HSCCC fractions were weighed after their pre-concentration on a rotary evaporator at $25^{\circ} \mathrm{C}$ and freeze-drying.

\section{LC-DAD-ESI-MS/MS analysis}

The eluates from the RP-C ${ }_{18}$ cartridge as well as a crude extract (Figure 1) and the HSCCC fractions (Figures 2 and 3) were analysed by LC-DAD-ESI-MS/MS using an LCMS-8030 mass spectrometric system coupled to an LC-20ADXR pump with a gradient elution mode at $40^{\circ} \mathrm{C}$ in the acetonitrile (A) and 2\% aqueous formic acid (B) system: $5 \% \mathrm{~A}$ in $\mathrm{B}$ at 0 min, a gradient to $60 \% \mathrm{~A}$ in $\mathrm{B}$ at $12 \mathrm{~min}$, then $80 \% \mathrm{~A}$ in $\mathrm{B}$ at $15 \mathrm{~min}$. The injection volume was $5 \mu \mathrm{L}$ and the flow rate was $0.5 \mathrm{~mL} / \mathrm{min}$. LC-DAD-ESI-MS/MS analyses were conducted on a $100 \mathrm{~mm} \times 4.6 \mathrm{~mm}$ I.D., $5.0 \mu \mathrm{m}$ Kinetex $\mathrm{C}_{18}$ chromatographic column from Phenomenex (Torrance, United States).

The LC-MS/MS system was controlled with LabSolutions software (Shimadzu, Japan), which was operated in a negative mode, at electrospray voltage of $4.5 \mathrm{kV}$, capillary temp. of $250^{\circ} \mathrm{C}$, and $\mathrm{N}_{2}$ used as the sheath gas. Scan range was from $m / z, 100$ to 2000 . Argon was used to improve trapping efficiency and as the collision gas for CID experiments. The collision energy for MS analyses was set at $50 \mathrm{~V}$.

\section{RESULTS AND DISCUSSION}

\section{MS/MS analysis of saponins}

The first study by Mroczek et al. [2012, 2019] on B. vulgaris L. cv. Red Sphere reported thirteen saponins with pentose and hexose substituents. Another research on saponins in B. vulgaris L. cv. Nochowski conducted by Mikołajczyk-Bator et al. [2016] revealed 27 acetal-, dioxolane- as well as pentose/hexose-type saponins.

In this study, the MS/MS analysis of the crude extract of Beta vulgaris L. (Figure 1) revealed the presence of thirteen acetal-, dioxolane- as well as pentose/hexose-type saponins. All of the identified saponins and their MS/MS data are listed in Table 1.

The saponins detected in our research are derivatives of oleanolic acid. The MS/MS data show the presence of five acetal- and two dioxolane-type substituents, which have been never described in B. vulgaris L. cv. Red Sphere. These types 


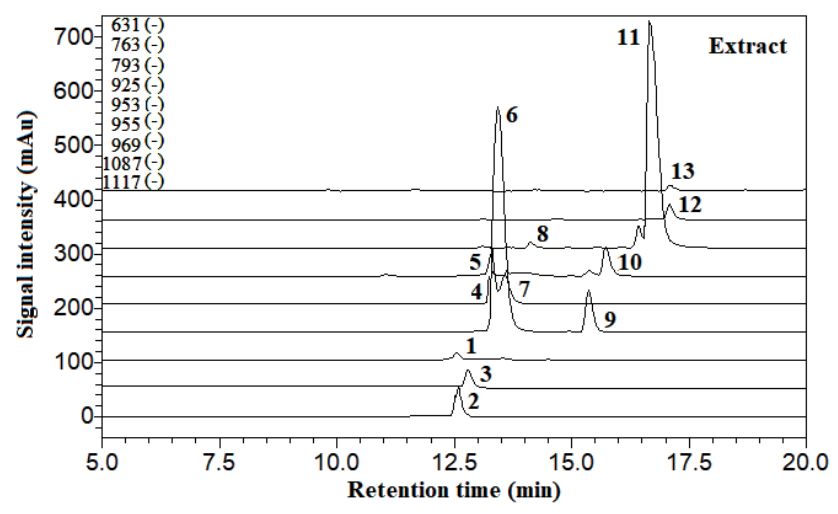

FIGURE 1. ESI-MS chromatogram of saponins from B. vulgaris L. cultivar Red Sphere extract.

of compounds were found by Mikołajczyk-Bator [2016] in B. vulgaris L. cv. Nochowski.

Fragmentation of saponins with oleanolic acid as the aglycone leads to yielding the daughter ion $[\mathrm{M}-\mathrm{H}]^{-}$at $\mathrm{m} / \mathrm{z} 631$ which corresponds to hexuronic acid-oleanolic acid. The simplest saponin with the pseudomolecular ion $[\mathrm{M}-\mathrm{H}]^{-}$at $m / z 631$ (peak 13 with $\mathrm{t}_{\mathrm{R}}=17.1 \mathrm{~min}$ ) was identified in the studied B. vulgaris L. extract. As expected, this compound (13, HexUA-oleanolic acid) fragmented to $m / z 455$ which corresponded to oleanolic acid. HexUA-oleanolic acid was previously identified in the B. vulgaris L. cv. Red Sphere [Mroczek et al., 2012, 2019].

The peak $12\left(t_{\mathrm{R}}=17.1 \mathrm{~min}\right)$ corresponded to the compound which exhibited the pseudomolecular ion $[\mathrm{M}-\mathrm{H}]^{-}$at $\mathrm{m} / \mathrm{z}$ 763. The fragmentation of this compound (12) yielded daughter ions at $m / z, 631$ and 455 because of the losses of pentose (132 Da) and hexuronic acid (176 Da), and therefore compound $\mathbf{1 2}$ was identified as Pen-HexUA-oleanolic acid.
Compound 12 was previously identified in the B. vulgaris L. cultivars Red Sphere and Nochowski [Mikołajczyk-Bator et al., 2016; Mroczek et al., 2012, 2019].

Peaks $\mathbf{8}\left(t_{R}=14.1 \mathrm{~min}\right)$ and $\mathbf{1 1}\left(t_{R}=16.7 \mathrm{~min}\right)$ corresponded to compounds with the identical pseudomolecular ions [M-H] ${ }^{-}$at $m / z 793$ and aglycone ions at $m / z 455$ which correspond to oleanolic acid. The fragmentation of the pseudomolecular ion $[\mathrm{M}-\mathrm{H}]^{-}$at $m / z, 793$ for compound 8 yielded daughter ions at $\mathrm{m} / \mathrm{z}, 631$ and 455 because of the losses of $162 \mathrm{Da}$ and $176 \mathrm{Da}$, confirming the presence of hexose and hexuronic acid. Finally, compound 8 was identified as Hex-HexUA-oleanolic acid. However, the fragmentation of compound $\mathbf{1 1}$ with the same pseudomolecular ion $[\mathrm{M}-\mathrm{H}]^{-}$at $\mathrm{m} / \mathrm{z} .793$ resulted in the formation of daughter ions at $m / z 673$ and 631, indicating the loss of $120 \mathrm{Da}$ and $162 \mathrm{Da}$ characteristic for the acetal-type substituent; and this compound can be assigned to Act-HexUA-oleanolic acid. The research of saponins profile in the B. vulgaris L. cv. Red Sphere did not reveal the presence of compound 11 [Mroczek et al., 2012, 2019] but this compound was previously observed in the B. vulgaris L. cv. Nochowski [Mikołajczyk-Bator et al., 2016]. The structure of compound $\mathbf{1 1}$ was determined by Yoshikawa et al. [1996] who named this saponin betavulgaroside IV.

The identical pseudomolecular ions $[\mathrm{M}-\mathrm{H}]^{-}$at $\mathrm{m} / \mathrm{z} 925$ were ascribed to peaks $\mathbf{5}\left(\mathrm{t}_{\mathrm{R}}=13.3 \mathrm{~min}\right)$ and $\mathbf{1 0}\left(\mathrm{t}_{\mathrm{R}}=15.8 \mathrm{~min}\right)$. These saponins consisted of the same aglycone ion at $m / z$ 455, corresponding to oleanolic acid. Moreover, the daughter ions at $m / z 631$ and 793 (losses of pentose (132 Da) and hexose (162 Da), respectively) were observed for both saponins. The compounds 5 and $\mathbf{1 0}$ (Pen-Hex-HexUA-oleanolic acids) were previously identified in B. vulgaris L. cv. Red Sphere [Mroczek et al., 2012, 2019].

Peaks $4\left(\mathrm{t}_{\mathrm{R}}=13.3 \mathrm{~min}\right)$ and $7\left(\mathrm{t}_{\mathrm{R}}=13.6 \mathrm{~min}\right)$ corresponded to compounds which revealed pseudomolecular ion $[\mathrm{M}-\mathrm{H}]^{-}$

TABLE 1. Saponins tentatively identified by negative ion ESI-MS/MS in B. vulgaris L. cultivar Red Sphere.

\begin{tabular}{cllccc}
\hline No. & Saponin structure & $\mathrm{t}_{\mathrm{R}}[\mathrm{min}]$ & $\mathrm{m} / z[\mathrm{M}-\mathrm{H}]^{-}$ & $\mathrm{m} / \mathrm{z}$ from MS/MS of [M-H] \\
\hline 1 & HexUA-Hex-HexUA-oleanolic acid* & 12.5 & 969 & unknown \\
2 & Act-Hex-Hex-HexUA-oleanolic acid & 12.5 & 1117 & $997 ; 955 ; 835 ; 793 ; 631 ; 455$ \\
3 & Act-Hex-Pen-HexUA-oleanolic acid & 12.8 & 1087 & $967 ; 925 ; 763 ; 631 ; 455$ \\
4 & Diox-Hex-HexUA-oleanolic acid & 13.3 & 953 & $909 ; 793 ; 631 ; 455$ \\
5 & Pen-Hex-HexUA-oleanolic acid & 13.3 & 925 & $793 ; 631 ; 455$ \\
6 & Act-Hex-HexUA-oleanolic acid & 13.5 & 955 & $835 ; 793 ; 673 ; 631 ; 455$ \\
7 & Diox-Hex-HexUA-oleanolic acid & 13.6 & 953 & $909 ; 793 ; 631 ; 455$ \\
8 & Hex-HexUA-oleanolic acid & 14.1 & 793 & $631 ; 455$ \\
9 & Act-Hex-HexUA-oleanolic acid & 15.4 & 955 & $835 ; 793 ; 673 ; 631 ; 455$ \\
10 & Pen-Hex-HexUA-oleanolic acid & 15.8 & 925 & $793 ; 631 ; 455$ \\
11 & Act-HexUA-oleanolic acid & 16.7 & 793 & $673 ; 631 ; 455$ \\
12 & Pen-HexUA-oleanolic acid & 17.1 & 763 & $631 ; 455$ \\
13 & HexUA-oleanolic acid & 17.1 & 631 & 455 \\
\hline
\end{tabular}

*proposed structure Hex - hexose; Pen - pentose; HexUA - hexuronic acid; Act - acetal substituent; Diox - dioxolane substituent. 
TABLE 2. Saponin distribution in the recovered HSCCC fractions obtained from B. vulgaris L. cultivar Red Sphere extract.

\begin{tabular}{|c|c|c|c|c|c|c|c|c|c|c|c|c|c|c|}
\hline \multirow{2}{*}{ No. } & \multirow{2}{*}{$m / z[\mathrm{M}-\mathrm{H}]^{-}$} & \multicolumn{12}{|c|}{ Relative content of pigments (\%)* } & \multirow{2}{*}{$\begin{array}{c}\text { Total HPLC } \\
\text { peak area }\left(\times 10^{-5}\right)\end{array}$} \\
\hline & & 1 & 2 & 3 & 4 & 5 & 6 & 7 & 8 & 9 & 10 & 11 & 12 & \\
\hline 1 & 969 & & & & & & & & 60.7 & 26.4 & 12.9 & & & 0.9 \\
\hline 2 & 1117 & & & & 80.3 & 19.7 & & & & & & & & 37.8 \\
\hline 3 & 1087 & & & 86.7 & 13.3 & & & & & & & & & 33.8 \\
\hline 4 & 953 & & & & & & 71.7 & 28.3 & & & & & & 30.1 \\
\hline 5 & 925 & & & & & & & 30.0 & 41.0 & 29.0 & & & & 20.2 \\
\hline 6 & 955 & & & 0.8 & 78.0 & 21.2 & & & & & & & & 294.8 \\
\hline 7 & 953 & & & & & & 54.6 & 45.4 & & & & & & 36.6 \\
\hline 8 & 793 & & & & & & & & & & 14.3 & 71.4 & 14.3 & 7.0 \\
\hline 9 & 955 & 10.0 & 63.3 & 26.7 & & & & & & & & & & 53.1 \\
\hline 10 & 925 & & & & 59.4 & 24.2 & 16.4 & & & & & & & 44.4 \\
\hline 11 & 793 & 8.0 & 68.0 & 11.0 & 13.0 & & & & & & & & & 104.6 \\
\hline 12 & 763 & & 12.0 & 13.2 & 18.0 & 48.1 & 8.7 & & & & & & & 19.4 \\
\hline 13 & 631 & & & & & 12.6 & 12.9 & 74.5 & & & & & & 3.5 \\
\hline \multicolumn{2}{|c|}{ Fraction mass (mg) } & 30.3 & 94.2 & 55.2 & 31.2 & 30.9 & 6.0 & 6.6 & 3.0 & 1.5 & 0.9 & 0.9 & 0.6 & \\
\hline
\end{tabular}

*analysed by LC-MS.

at $m / z, 953$ and fragment ions at $m / z, 909,793,631$, and 455. These compounds were characterised for the first time in B. vulgaris L. cv. Red Sphere. The fragmentation of the $[\mathrm{M}-\mathrm{H}]$ primarily yielded daughter ions at $\mathrm{m} / \mathrm{z} 909$ and 793 because of the loss of $\mathrm{CO}_{2}$ and a dioxolane-type substituent, respectively. The MS/MS data exhibited additionally daughter ions at $\mathrm{m} / \mathrm{z} 631$ and 455, being characteristic for hexuronic acid-oleanolic acid and oleanolic acid. These two compounds were identified as Diox-Hex-HexUA-oleanolic acids. It is worth noting that saponins with dioxolane-type substituents were detected in B. vulgaris L. cv. Red Sphere for the first time ever, but this type of the structure was determined by Yoshikawa et al. [1996] who named it betavulgaroside I. The compounds 6 and 9 with $t_{R}$ 13.5 and $15.4 \mathrm{~min}$, respectively, exhibited identical [M-H] ions at $m / z, 955$, which corresponded to acetal-type substituent saponins because of the loss of $120 \mathrm{Da}$ (daughter ion at $\mathrm{m} / \mathrm{z}$ 835) and $162 \mathrm{Da}$ (daughter ion at $m / z$ 793) during fragmentation. The daughter ion at $m / z 835$ was not noticed during the fragmentation of compounds $\mathbf{6}$ and $\mathbf{9}$ identified by Mroczek et al. [2019] in B. vulgaris L. cv. Red Sphere. These acetal-saponins (compounds $\mathbf{6}$ and $\mathbf{9}$ ) were also identified by Mikołajczyk-Bator et al. [2016] in B. vulgaris L. cv. Nochowski. Based on the MS/MS fragmentation of compound $\mathbf{6}$ and $\mathbf{9}$ as well as previous MS/MS data [Mikołajczyk-Bator et al., 2016], it can be deduced that these molecules consisted of aglycone ion at $\mathrm{m} / \mathrm{z}, 455$ - oleanolic acid as well as acetal-type substituent, hexose and hexuronic acid. Taking into account the above elucidations, compounds $\mathbf{6}$ and $\mathbf{9}$ were designated as Act-Hex-HexUA-oleanolic acid.

Peak $1\left(t_{R}=12.5 \mathrm{~min}\right)$ corresponding to the compound revealing the pseudomolecular ion $[\mathrm{M}-\mathrm{H}]^{-}$at $m / z 969$ was tentatively identified as hexuronic acid-hexose-hexuronic acid derivative of oleanolic acid (HexUA-Hex-HexUA-oleanolic acids). The concentration of compound $\mathbf{1}$ was not sufficient to identify daughter ions. Mikołajczyk-Bator et al. [2016] identified presumably identical saponin in B. vulgaris L. cv. Nochowski. The elution of compound $\mathbf{1}$ in further HSCCC fractions indicates that it is not an acetal-type saponin, because such saponins are eluted in early fractions.

The compound $\mathbf{3}\left(\mathrm{t}_{\mathrm{R}}=12.8 \mathrm{~min}\right)$ was characterised by the pseudomolecular ion $[\mathrm{M}-\mathrm{H}]^{-}$at $\mathrm{m} / \mathrm{z} 1087$ and fragment ions at $m / z$ 967, 925, 763, 631, and 455. The fragmentation of compound $\mathbf{3}$ resulted in the formation of primary daughter ions at $\mathrm{m} / \mathrm{z}, 967$ and 925 because of the loss of $120 \mathrm{Da}$ and $162 \mathrm{Da}$ (cleavage and loss of the acetyl-type substituent, respectively). The presence of the daughter ions at $m / z, 763$ and 631 indicated the loss of the hexose and pen-

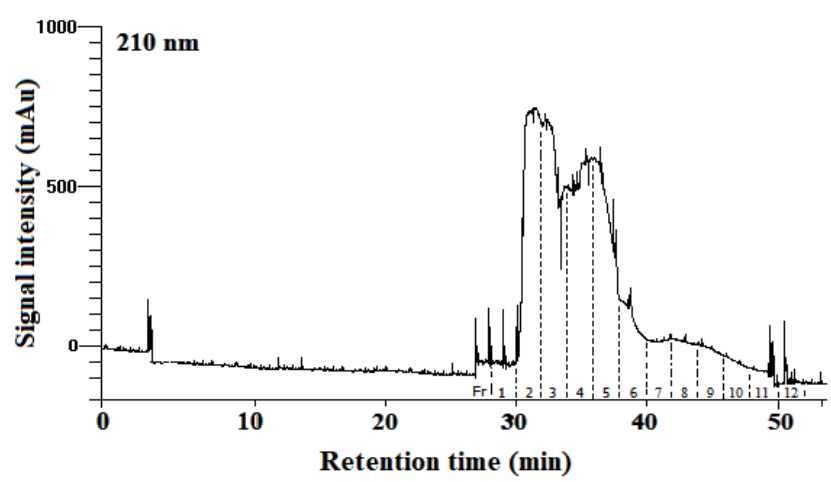

FIGURE 2. HSCCC chromatogram of B. vulgaris L. cultivar Red Sphere extract $(300 \mathrm{mg})$ separated into 12 fractions in a solvent system: TBME-BuOH-ACN-H2O $(1: 2: 1: 5, v / v / v / v)$ at a flow rate of $3.0 \mathrm{~mL} / \mathrm{min}$ in the head-to-tail mode; velocity $860 \mathrm{rpm}$; optical detection at a wavelength of $210 \mathrm{~nm}$. 
tose from the structure of compound 3. Finally, this compound was identified as Act-Hex-Pen-HexUA-oleanolic acid. Compound $\mathbf{3}$, named as betavulgaroside IX, was identified for the first time by Yoshikawa et al. [1996]. Betavulgaroside IX was only identified in Nochowski cv. by Mikołajczyk-Bator et al. [2016].

The MS spectra of the compound $t_{R}=12.5$ min the pseudomolecular ion [M-H] $]^{-}$at $m / z 1117$ which fragmented into ions at $m / z$,997, 955, 835, 793, 631, and 455, indicated the presence of saponin with acetal-type substituent. The fragmentation of this compound (2) resulted in the formation of primary daughter ions at $\mathrm{m} / \mathrm{z} 997$ and 955 (losses of 120 and $162 \mathrm{Da}$ ) corresponding to the cleavage and loss of the acetal-type substituent, respectively. The presence of the daughter ions at $\mathrm{m} / \mathrm{z}, 793$ and 631 indicated the loss of the two hexoses from the structure of compound 2 . The daughter ions at $\mathrm{m} / \mathrm{z} 631$ and 455 confirmed the presence of hexuronic acid-oleanolic acid and oleanolic acid, respectively. Taking into account the above elucidations, compound $\mathbf{2}$ was identified as Act-Hex-Hex-HexUA-oleanolic acid. The compound $\mathbf{2}$ has been never identified in $B$. vulgaris L. cv. Red Sphere but was identified in Nochowski cv. by Mikołajczyk-Bator et al. [2016]. Moreover, compound $\mathbf{2}$ was thoroughly described using NMR by Yoshikawa et al. [1996] who named it betavulgaroside V.
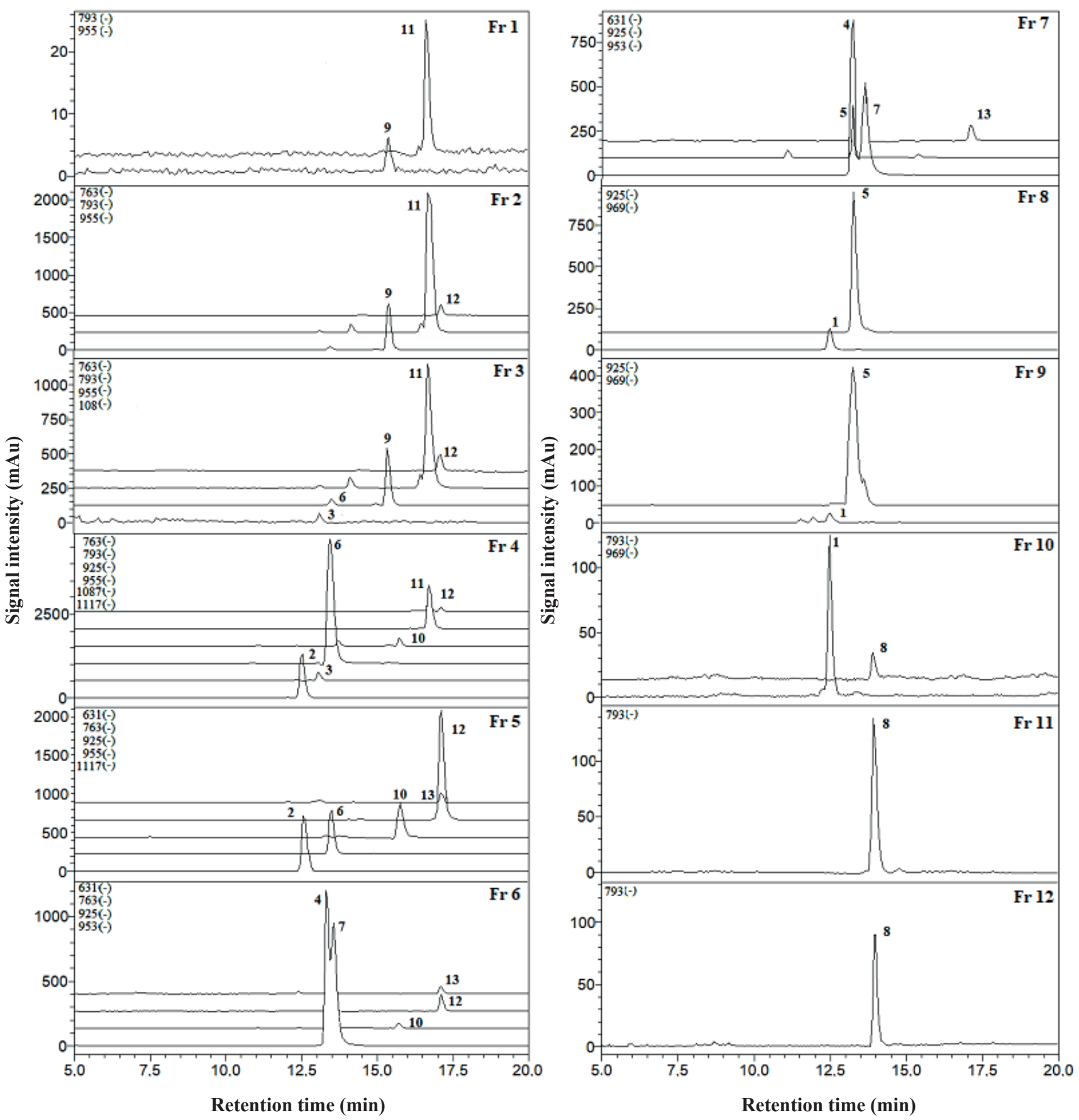

FIGURE 3. ESI-MS chromatograms of saponins analysed in the fractions (1-12) separated from the extract of B. vulgaris L. cultivar Red Sphere by HSCCC. 


\section{HSCCC separation of saponins}

The crude extract $(300 \mathrm{mg})$ was fractionated by the HSCCC technique and 12 fractions were collected and analysed by LC-DAD-ESI-MS/MS analysis (Table 2, Figures 1-3).

The HSCCC separation monitored at $210 \mathrm{~nm}$ (Figure 2) was realized in a new solvent system TBME-BuOH-ACN-H $-\mathrm{O}$ $(1: 2: 1: 5, v / v / v / v)$ in a head-to-tail mode which corresponds to the reversed-phase mode in HPLC. Saponins were previously separated by HSCCC technique in a solvent system TBME-BuOH-ACN- $\mathrm{H}_{2} \mathrm{O}(1: 3: 1: 5, v / v / v / v)$ showing retention of the stationary phase amounting to 35\% [Thakur et al., 2014], therefore, a new solvent system with higher retention was prepared. After the separation in the new solvent system, the retaining amount of stationary phase in the coil-system was calculated to be $47 \%$. Elution order and separation effectiveness of saponins in the HSCCC and the $\mathrm{C}_{18}$ reversed-phase HPLC were compared in order to demonstrate the complementarity of these techniques.

The most polar HexUA-Hex-HexUA-oleanolic acid (1) with the pseudomolecular ion [M-H]- at m/z 969 was eluted in fractions $8-10$ and it was completely separated from Act-Hex-Hex-HexUA-oleanolic acid (2) with the pseudomolecular ion at $\mathrm{m} / \mathrm{z}$ 1117. Separation of compounds $\mathbf{1}$ and $\mathbf{2}$ was not possible in the HPLC system applied due to their identical retention times, therefore, HSCCC allowed for their complete separation.

Likewise, compounds Act-Hex-Hex-HexUA-oleanolic acid (2) and Act-Hex-Pen-HexUA-oleanolic acid (3) differed by their elution profiles in the HPLC and HSCCC technique. Compound 2 ([M-H] at $m / z$ 1117) and compound $\mathbf{3}([\mathrm{M}-\mathrm{H}]$ at $m / z$ 1087) differed by one sugar moiety. Compound 2 with hexose in the structure as eluted later in the HSCCC than compound $\mathbf{3}$ with pentose. Different elution profiles of compounds $\mathbf{2}$ and $\mathbf{3}$ in the HPLC and the HSCCC mad their complete separation feasible.

Similar structures for Diox-Hex-HexUA-oleanolic acid (4) ([M-H]- at $\mathrm{m} / \mathrm{z}$ 953) and Pen-Hex-HexUA-oleanolic acid (5) $([\mathrm{M}-\mathrm{H}]-$ at $\mathrm{m} / \mathrm{z}$ 925) presumably contributed to their coelution in the HPLC system. Compound $\mathbf{4}$ consisted of dioxolane-type substituent, whereas compound $\mathbf{5}$ consisted of a pentose. The elution order of compounds $\mathbf{4}$ and $\mathbf{5}$ was identical in the HPLC and the HSCCC but the HSCCC technique enabled their quite effective separation.

A complete separation of Pen-Hex-HexUA-oleanolic acid (5) $([\mathrm{M}-\mathrm{H}]-$ at $m / z$ 925) and Act-Hex-HexUA-oleanolic acid (6) $([\mathrm{M}-\mathrm{H}]-$ at $\mathrm{m} / \mathrm{z}$ 955) was observed in spite of their similar chromatographic properties indicated in the $\mathrm{C}_{18}$-HPLC system. The difference in the structure consists in the presence of the acetal-type substituent in compound $\mathbf{6}$ instead of pentose in compound $\mathbf{5}$. The presence of the acetal-type substituent presumably contributed to the faster elution of compound $\mathbf{6}$ in comparison to compound $\mathbf{5}$ in the HSCCC system. Similarly, the separation of the compounds $\mathbf{5}$ and $\mathbf{6}$ by HSCCC and HPLC also proves the complementarity of the two separation systems.

The principal compound present in the extract, Act-Hex-HexUA-oleanolic acid (6) ([M-H] ${ }^{-}$at $m / z$ 955), differed from Diox-Hex-HexUA-oleanolic acid (4) and Diox-Hex-HexUA-oleanolic acid (7) $\left([\mathrm{M}-\mathrm{H}]^{-}\right.$at $\mathrm{m} / \mathrm{z}$ 953) by the presence of acetal-type substituent in compound $\mathbf{6}$ instead of dioxolane-type substituent in compound $\mathbf{4}$ and $\mathbf{7}$. The differences in the structures translated into their properties during separation by the HSCCC technique. Acetal-type saponin (ActHex-HexUA-oleanolic acid, compound 6) was eluted faster than Diox-Hex-HexUA-oleanolic acid (compounds 4 and 7).

Separation of Hex-HexUA-oleanolic acid (8) $([\mathrm{M}-\mathrm{H}]$ at $\mathrm{m} / \mathrm{z}$ 793) which was present mainly in the fractions 11 and 12 was very effective. This saponin only partially coeluted with HexUA-Hex-HexUA-oleanolic acid in fraction 10 in the HSCCC.

Act-Hex-HexUA-oleanolic acid (9) ([M-H] at $\mathrm{m} / \mathrm{z}$ 955) and Pen-Hex-HexUA-oleanolic acid (10) ([M-H] at $\mathrm{m} / 2$ 925), similarly to compounds $\mathbf{5}$ and $\mathbf{6}$, were completely separated by the HSCCC according to differences in their structures (acetal-type substituent and pentose, respectively). Similarities can also be seen in the elution order.

Furthermore, comparison of the elution order of Act-HexUA-oleanolic acid (11) ([M-H] at $\mathrm{m} / \mathrm{z}$, 793) and Pen-HexUA-oleanolic acid (12) ([M-H] - at $m / z$ 763) confirmed that the acetal-type saponins are eluted faster in the HSCCC system than the pentose-type saponins. Because compounds $\mathbf{1 1}$ and $\mathbf{1 2}$ are closely related, their complete separation by HSCCC was impossible. The separation of these saponins could be feasible in highly polar solvent systems with salts [Spórna-Kucab et al., 2013a].

HexUA-oleanolic acid (13) $\left([\mathrm{M}-\mathrm{H}]^{-}\right.$at $m / z$ 631), eluted as the last saponin in the HPLC, was not completely separated by the HSCCC technique but its different elution profiles in the HPLC and the HSCCC systems afford the possibility for its recovery using both techniques.

\section{CONCLUSION}

In this study, separation of saponins from B. vulgaris L., cultivar Red Sphere, has been realized for the first time using high-speed counter-current chromatography in a new solvent system consisting of tert-butyl-methyl ether-butanol-acetonitrile-water. The previously described [Thakur et al., 2014] solvent system for the separation of saponins by the HSCCC had much lower retention of the stationary phase, therefore, the new solvent system had been prepared. Separation and concentration of the compounds during the HSCCC process enabled tentative identification of 13 saponins by MS/MS technique. Nine saponins were detected for the first time in B. vulgaris L. cv. Red Sphere. Additionally, saponin with the pseudomolecular ion [M-H] at $\mathrm{m} / \mathrm{z} 969$ has been tentatively identified for the first time and its possible structure has been proposed.

Analysis of the saponin elution order showed some tendencies. Acetal-type saponins were eluted faster than pentose/hexose-type saponins as well as dioxolane-type saponins. Moreover, the saponins differed in the elution order in the HPLC and HSCCC systems, therefore, their elution in HSCCC is rather dependent on the steric conditions than on polarity. The combination of the HPLC and HSCCC results in complementary elution orders and makes them a very versatile tool for the isolation of saponins which may open up the possibility of utilizing these compounds commercially. 


\section{RESEARCH FUNDING}

This research was financed by the Polish National Science Centre for years 2019-2020 (Project No. 2019/03/X/ ST4/00968).

\section{CONFLICT OF INTEREST}

Authors declare no conflict of interest.

\section{REFERENCES}

1. Bruneton, J. (1995). Pharmacognosy. Phytochemistry, Medicinal Plants. Lavoisier Publishing, Paris, France, pp. 538-544.

2. Chhikara, N., Kushwaha, K., Sharma, P., Gat, Y., Panghal, A. (2019). Bioactive compounds of beetroot and utilization in food processing industry: A critical review. Food Chemistry, 272, 192-200.

3. Choi, S.J., Choi, J., Jeon, H., Bae, S., Ko, J., Kim, J., Yoon, K.D. (2015). Application of high-performance countercurrent chromatography for the isolation of steroidal saponins from Liriope plathyphylla. Journal of Separation Science, 38(1), 18-24.

4. Clifford, T., Howatson, G., West, D., Stevenson, J. (2015). Review: The potential benefits of red beetroot supplementation in health and disease. Nutrients, 7(4), 2801-2822.

5. da Silva, B.P., De Sousa, A.C., Silva, G.M., Mendes, T.P., Parente, J.P. (2002). A new bioactive steroidal saponin from Agave attenuata. Zeitschrift fur Naturforschung C - Journal of Biosciences, 57(5-6), 423-428.

6. de Lucca, A., Bland, J.M., Vigo, C.B., Cushion, M., Selitrennikoff, C.P., Peter, J., Walsh, T.J. (2002). CAY-1, a fungicidal saponin from Capsicum sp. fruit. Medical Mycology, 40(2), 131-137.

7. Figueiredo, F., Celano, R., Silva, D., Costa, F., Hewitson, P., Ignatova, S., Piccinelli, A., Leitão, S., Leitão, G. (2017). Countercurrent chromatography separation of saponins by skeleton type from Ampelozizyphus amazonicus for off-line ultra-high-performance liquid chromatography/high resolution accurate mass spectrometry analysis and characterisation. Journal of Chromatography A, 1481, 92-100.

8. González, A.G., Hernández, J.C., León, F., Padrón, J.I., Estévez, F., Quintana, J., Bermejo, J. (2003). Steroidal saponins from the bark of Dracaena draco and their cytotoxic activities. Journal of Natural Products, 66(6), 793-798.

9. Gosse, B., Gnabre, J., Bates, R.B., Dicus, C.W., Nakkiew, P., Huang, R.C.C. (2002). Antiviral saponins from Tieghemella heckelii. Journal of Natural Products, 65(12), 1942-1944.

10. Huang, H.C., Liao, S.C., Chang, F.R., Kuo, Y.H., Wu, Y.C. (2003). Molluscicidal saponins from Sapindus mukorossi, inhibitory agents of golden apple snails, Pomacea canaliculata. Journal of Agricultural and Food Chemistry, 51 (17), 4916-4919.

11. Jerz, G., Wybraniec, S., Gebers, N., Winterhalter, P. (2010). Target-guided separation of Bougainvillea glabra betacyanins by direct coupling of preparative ion-pair high-speed countercurrent chromatography and electrospray ionization mass-spectrometry. Journal of Chromatography A, 1217(27), 4544-4554.

12. Jerz, G., Skotzki, T., Fiege, K., Winterhalter, P., Wybraniec, S. (2008). Separation of betalains from berries of Phytolacca americana by ion pair high-speed counter-current chromatography. Journal of Chromatography A, 1190(1-2), 63-73.
13. Mikołajczyk-Bator, K., Błaszczyk, A., Czyżniejewski, M., Kachlicki, P. (2016). Characterisation and identification of triterpene saponins in the roots of red beets (Beta vulgaris L.) using two HPLC-MS systems. Food Chemistry, 192, 979-990.

14. Mroczek, A., Kapusta, I., Stochmal, A., Janiszowska, W. (2019). MS/MS and UPLC-MS profiling of triterpenoid saponins from leaves and roots of four red beet (Beta vulgaris L.) cultivars. Phytochemistry Letters, 30, 333-337.

15. Mroczek, A., Kapusta, I., Janda, B., Janiszowska, W. (2012). Triterpene saponin content in the roots of red beet (Beta vulgaris L.) cultivars. Journal of Agricultural and Food Chemistry, 60(50), 12397-12402.

16. Nemzer, B., Pietrzkowski, Z., Spórna, A., Stalica, P., Thresher, W., Michałowski, T., Wybraniec, S. (2011). Betalainic and nutritional profiles of pigment-enriched red beet root (Beta vulgaris L.) dried extracts. Food Chemistry, 127(1), 42-53.

17. Sparg, S.G., Light, M.E., Staden, J. (2004). Review: Biological activities and distribution of plant saponins. Journal of Ethnopharmacology, 94(2-3), 219-243.

18. Spórna-Kucab, A., Kumorkiewicz, A., Szmyr, N., Szneler, E., Wybraniec, S. (2019). Separation of betacyanins from flowers of Amaranthus cruentus L. in a polar solvent system by high-speed counter-current chromatography. Journal of Separation Science, 42(9), 1676-1685.

19. Spórna-Kucab, A., Milo, A., Kumorkiewicz, A., Wybraniec, S. (2018a). Studies on polar high-speed counter-current chromatographic systems in separation of amaranthine-type betacyanins from Celosia species. Journal of Chromatography B, 1073, 96-103.

20. Spórna-Kucab, A., Bernaś, K., Grzegorczyk, A., Malm, A., Skalicka-Woźnika, K., Wybraniec, S., (2018b). Liquid chromatographic techniques in betacyanin isomers separation from Gomphrena globosa L. flowers for the determination of their antimicrobial activities. Journal of Pharmaceutical and Biomedical Analysis, 161, 83-93.

21. Spórna-Kucab, A., Hołda, E., Wybraniec, S. (2016). High-speed counter-current chromatography in separation of betacyanins from flowers of red Gomphrena globosa L. cultivars. Journal of Chromatography B, 1033-1034, 421-427.

22. Spórna-Kucab, A., Ignatova, S., Garrard, I., Wybraniec, S. (2013a). Versatile solvent systems for the separation of betalains from processed Beta vulgaris L. juice using counter-current chromatography. Journal of Chromatography B, 941, 54-61.

23. Spórna-Kucab, A., Garrard, I., Ignatova, S., Wybraniec, S. (2015). New solvent systems for gradient-counter-current chromatography in separation of betanin and its derivatives from processed Beta vulgaris L. juice. Journal of Chromatography A, 1380, 29-37.

24. Thakur, M., Jerz, G., Tuwalska, D., Gilabert-Oriol, R., Wybraniec, S., Winterhalter, P. (2014). High-speed countercurrent chromatographic recovery and off-line electrospray ionization mass spectrometry profiling of bisdesmodic saponins from Saponaria officinalis possessing synergistic toxicity enhancing properties on targeted antitumor toxins. Journal of Chromatography B, 955-956, 1-9.

25. Traore, F., Faure, R., Ollivier, E., Gasquet, M., Azas, N., Debrauwer, L., Keita, A., Timon-David, P., Balansard, G. (2000). Structure and antiprotozoal activity of triterpenoid saponins from Glinus oppositifolius. Planta Medica, 66(4), 368-371. 
26. Voutquenne, L., Guinot, P., Thoison, O., Sevenet, T., Lavaud, C. (2003). Oleanolic glycosides from Pometia ridleyi. Phytochemistry, 64(3), 781-789.

27. Wybraniec, S., Jerz, G., Gebers, N., Winterhalter, P. (2010). Ion-pair high speed countercurrent chromatography fractionation of a high molecular weight variation of acyl-oligosaccharide linked betacyanins from purple bracts of Bougainvillea glabra. Journal of Chromatography B, 878(5-6), 538-550.

28. Wybraniec, S., Stalica, P., Jerz, G., Klose, B., Gebers, N., Winterhalter, P., Spórna, A., Szaleniec, M., Mizrahi, Y. (2009). Separation of polar betalain pigments from cacti fruits of Hylocereus polyrhizus by ion-pair high-speed countercurrent chromatography. Journal of Chromatography A, 1216(41), 6890-6899.
29. Yoshikawa, M., Murakami, T., Kadoya, M., Yamahara, J., Matsuda, H. (1998). Medical Foodstuffs. XV. Sugar Beet. (2): Structures of Betavulgarosides V, VI, VII, VIII, IX and X from the roots and leaves of sugar beet (Beta vulgaris L., Chenopodiaceae). Chemical and Pharmaceutical Bulletin, 46, 1758-1763.

30. Yoshikawa, M., Murakami, T., Kadoya, M., Yamahara, J., Matsuda, H. (1996). Medical Foodstuffs. III. Sugar Beet. (1): Hypoglycemic oleanolic acid oligoglycosides, Betavulgarosides I, II, III, and IV, from the root of Beta vulgaris L. (Chenopodiaceae). Chemical and Pharmaceutical Bulletin, 44, 1212-1217.

Submitted: 10 September 2019. Revised: 22 November and 9 December 2019. Accepted: 10 January 2020. Published on-line: 5 February 2020. 